MLM- -3554

DE89 004433

\title{
Cost Estimate for Muddy Water Palladium Production Facility at Mound
}

\author{
Ronald K. McAdams
}

Issued: November 30, 1988

\section{DISCLAIMER}

This report was prepared as an account of work sponsored by an agency of the United States Government. Neither the United States Government nor any agency thereof, nor any of their employees, makes any warranty, express or implied, or assumes any legal liability or responsibility for the accuracy, completeness, or usefulness of any information, apparatus, product, or process disclosed, or represents that its use would not infringe privately owned rights. Reference herein to any specific commercial product, process, or service by trade name, trademark, manufacturer, or otherwise does not necessarily constitute or imply its endorsement, recommendation, or favoring by the United States Government or any agency thereof. The views and opinions of authors expressed herein do not necessarily state or reflect those of the United States Government or any agency thereof.

\section{MOUND}

operated by

EGIL MOUND APPLIED TECHNOLOGIES

P.O. Box 3000, Miamisburg, Ohio 45343-0987

for the

U. S. DEPARTMENT OF ENERGY

Contract No. DE-AC04-88DP43495 


\section{DISCLAIMER}

Portions of this document may be illegible in electronic image products. Images are produced from the best available original document. 


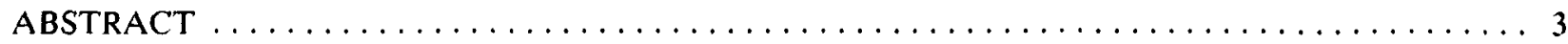

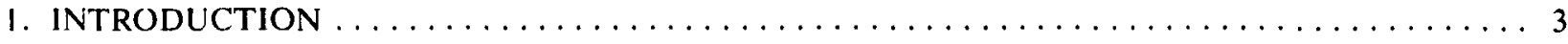

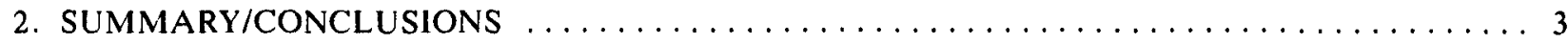

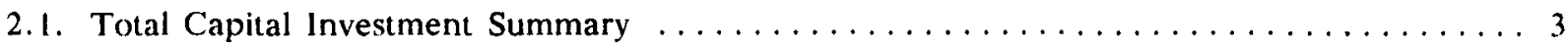

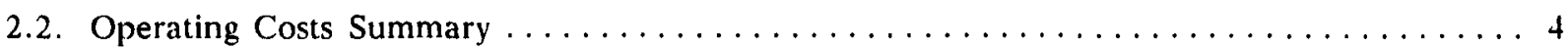

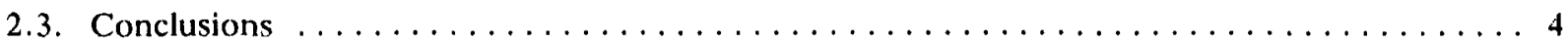

3. PRODUCTION FACILITY DESCRIPTION $\ldots \ldots \ldots \ldots \ldots \ldots \ldots \ldots \ldots \ldots \ldots \ldots \ldots \ldots$

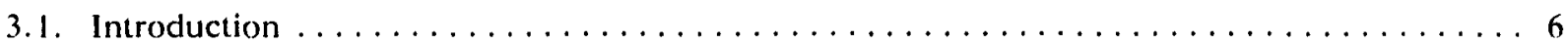

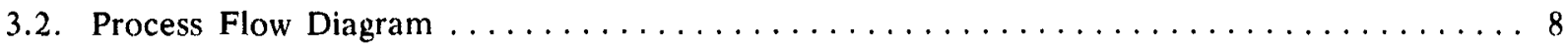

4. TOTAL CAPITAL INVESTMENT CALCULATIONS $\ldots \ldots \ldots \ldots \ldots \ldots \ldots \ldots \ldots \ldots \ldots$

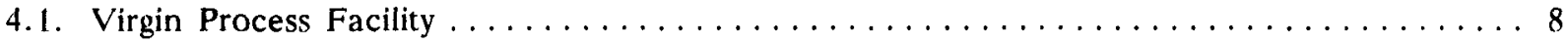

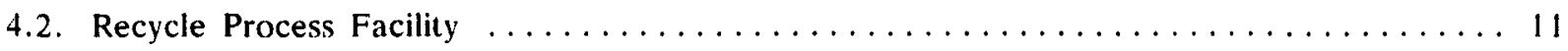

5. TOTAL OPERATING COST CALCULATIONS $\ldots \ldots \ldots \ldots \ldots \ldots \ldots \ldots \ldots \ldots \ldots$

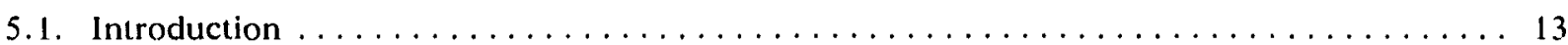

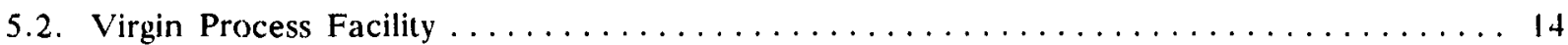

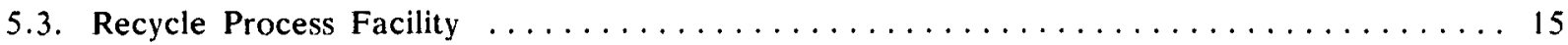

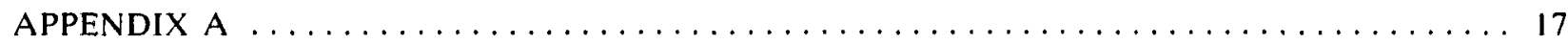

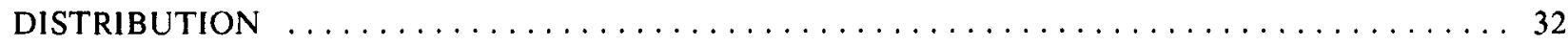




\section{Abstract}

An economic feasibility study was performed on the "Muddy Water" lowchlorine content palladium powder production process developed by Mound. The total capital investment and total operating costs (dollars per gram) were determined for production batch sizes of 1 to $10 \mathrm{~kg}$ in $1-\mathrm{kg}$ increments. The report includes a brief description of the Muddy Water process, the process flow diagram, and material balances for the various production batch sizes. Two types of facilities were evaluated -- one for production of new, "virgin" palladium powder, and one for recycling existing material.

The total capital investment for virgin facilities ranged from $\$ 600,000$ to $\$ 1.3$ million for production batch sizes of 1 to $10 \mathrm{~kg}$, respectively. The range for recycle facilities was $\$ 1$ to $\$ 2.3$ million. The total operating cost for $100^{\circ} \%$ acceptable powder production in the virgin facilities ranged from $\$ 23$ per gram for a $1-\mathrm{kg}$ production batch size to $\$ 8$ per gram for a $10-\mathrm{kg}$ batch size. Similarly for recycle facilities, the total operating cost ranged from $\$ 34$ per gram to $\$ 5$ per gram. The total operating cost versus product acceptability (ranging from $50 \%$ to $1000^{\circ}$ acceptability) was also evaluated for both virgin and recycle facilities. Because production sizes studied vary widely and because scaleup factors are unknown for batch sizes greater than $1 \mathrm{~kg}$, all costs are "order-of-magnitude" estimates. All costs reported are in 1987 dollars.

\section{Introduction}

A process for preparing low-chlorine content palladium powder ("Muddy Water" process) has successfully been developed by Mound personnel at the request of Los Alamos National Laboratory (LANL). As an extension of this development work, an economic feasibility study was requested to determine the total capital investment and operating costs for various sizes of process scale-ups based on the bench-scale Muddy Water process. This information will be used in the evaluation of the "make versus buy" decision by LANL (i.e., to make the capital investment and produce the palladium powder within the DOE or purchase this material from a commercial manufacturer who will meet LANL's product specifications).

The following report provides cost estimates on the total capital investment and operating expenses for $1-$ to $10-\mathrm{kg}$ production batch sizes. These estimates have been generated for both virgin and recycle facilities. Because there are many uncertainties involved, (including annual material requirements, scaling effects on the process above $1-\mathrm{kg}$ batch sizes, an undetermined location, and whether the facility will be dedicated to virgin or recycle material both), these are considered order-of-magnitude estimates with a probable accuracy of $-40 \%$ to $+50 \%$. All cost figures are in 1987 dollars.

\section{Summary/Conclusions 2.1 Total Capital Investment Summary}

Figure 1 provides a plot of the estimated total capital cost for both virgin and recycle facilities at various production batch sizes. Costs range from approximately $\$ 613,000$ to $\$ 1.3$ million for virgin facilities, and from approximately $\$ 1.03$ million to $\$ 2.3$ million for recycle facilities. The major contributors to the higher cost of the recycle facilities are the glovebox, glovebox purge system, and room modification requirements. The itemized costs used to generate the total capital investment estimates are provided on Tables 1 and 2. All tables are lound in Appendix A. Details on how the itemized costs were generated are provided in 


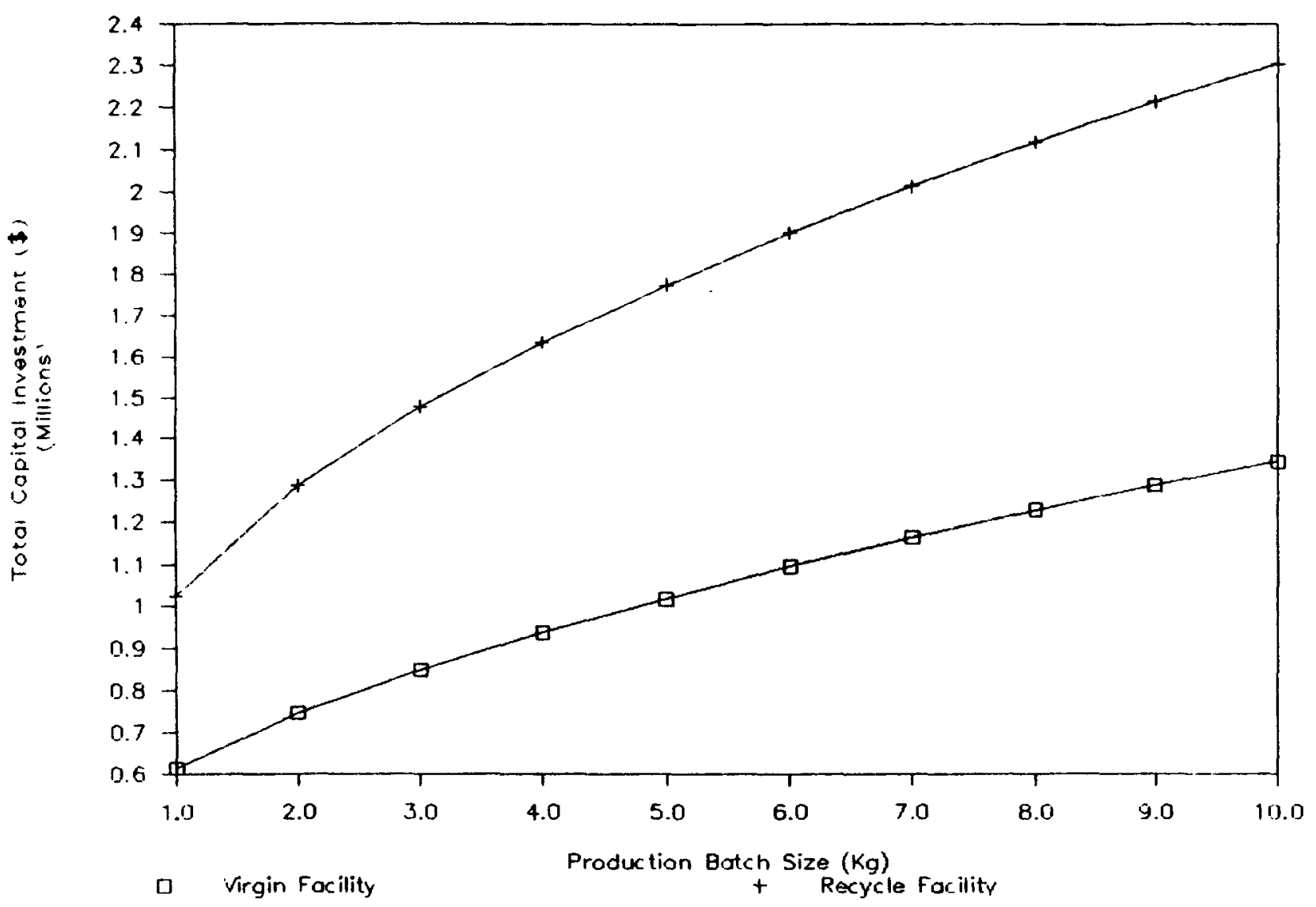

FIGURE 1 - Palladium production facility -- total capital investment versus batch size.

Section 4, "Total Capital Investment Calculations."

\subsection{Operating Costs Summary}

Figures 2 and 3 provide plots of total operating costs $(\$ / g)$ versus product acceptability for virgin and recycle facility operations, respectively. "Product acceptability" is defined as that quantity of product which meets the required specifications. All costs associated with manufacturing an unacceptable product must be added to the acceptable product costs to realistically represent the total expenses incurred in making a usable final product. Therefore, a process with a $50 \%$ product acceptability rate costs essentially twice as much, on a dollars per gram basis, than a process with a $100 \%$ acceptability rate (only the palladium costs are not re-incurred). Plots of acceptability rates in the $50 \%$ to $100 \%$ range are provided. The individual values used in Figures 2 and 3 are listed in Table 4.

Table 3 provides the itemized costs, in dollars per gram, for various batch sizes and virgin/ recycle facilities. Details on how these itemized costs were generated are provided in Section 5, "Total Operating Cost Calculations."

\subsection{Conclusions}

The total capital investment cost estimates are essentially linear with respect to batch size, with the recycle facility plot having a slightly greater slope than that of the virgin facility. Because of this linear relationship, the total capital costs are minimized by selecting the smallest production batch size that meets the annual material requirements. 


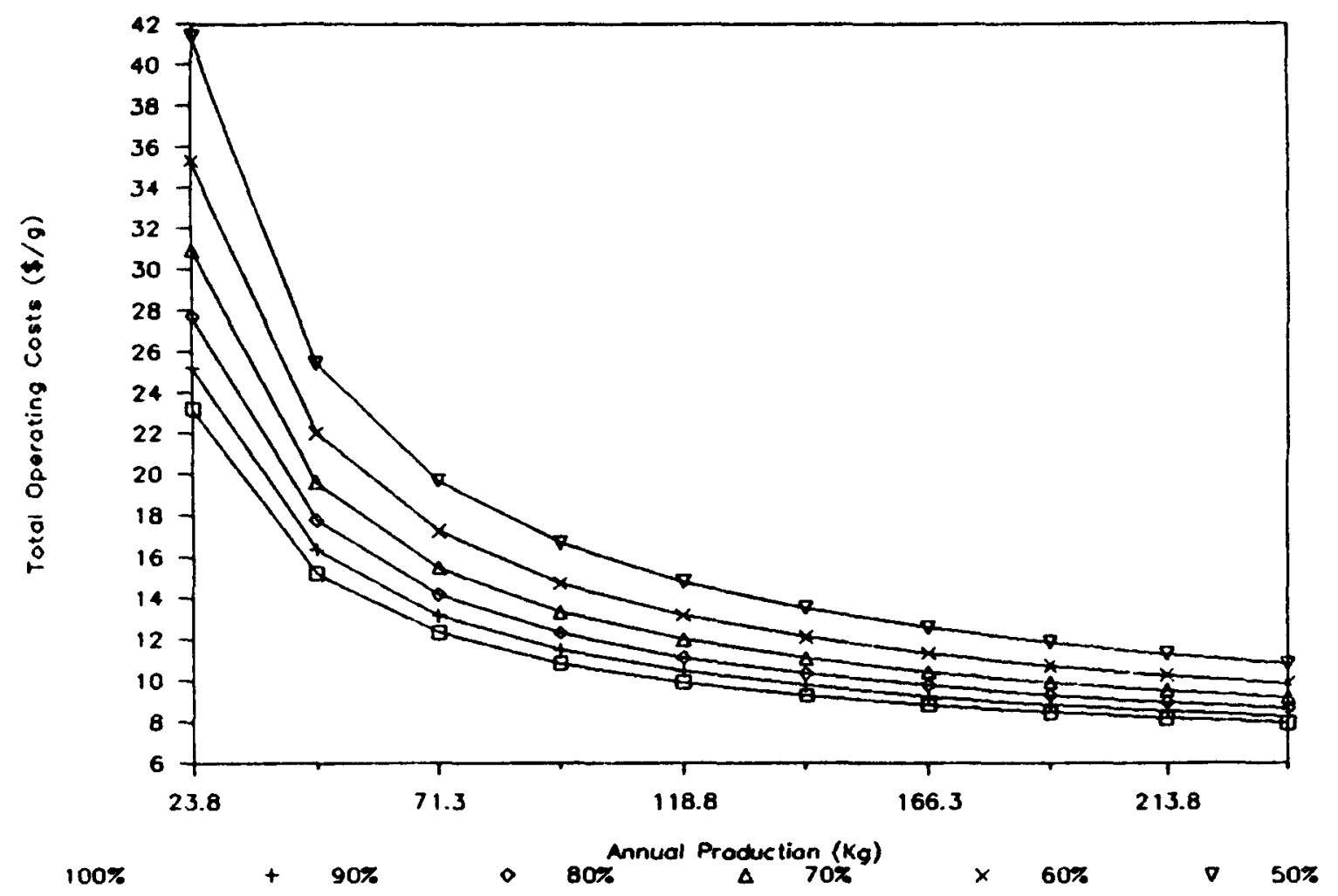

FIGURE 2 - Operating cost versus product acceptability -- virgin facility.

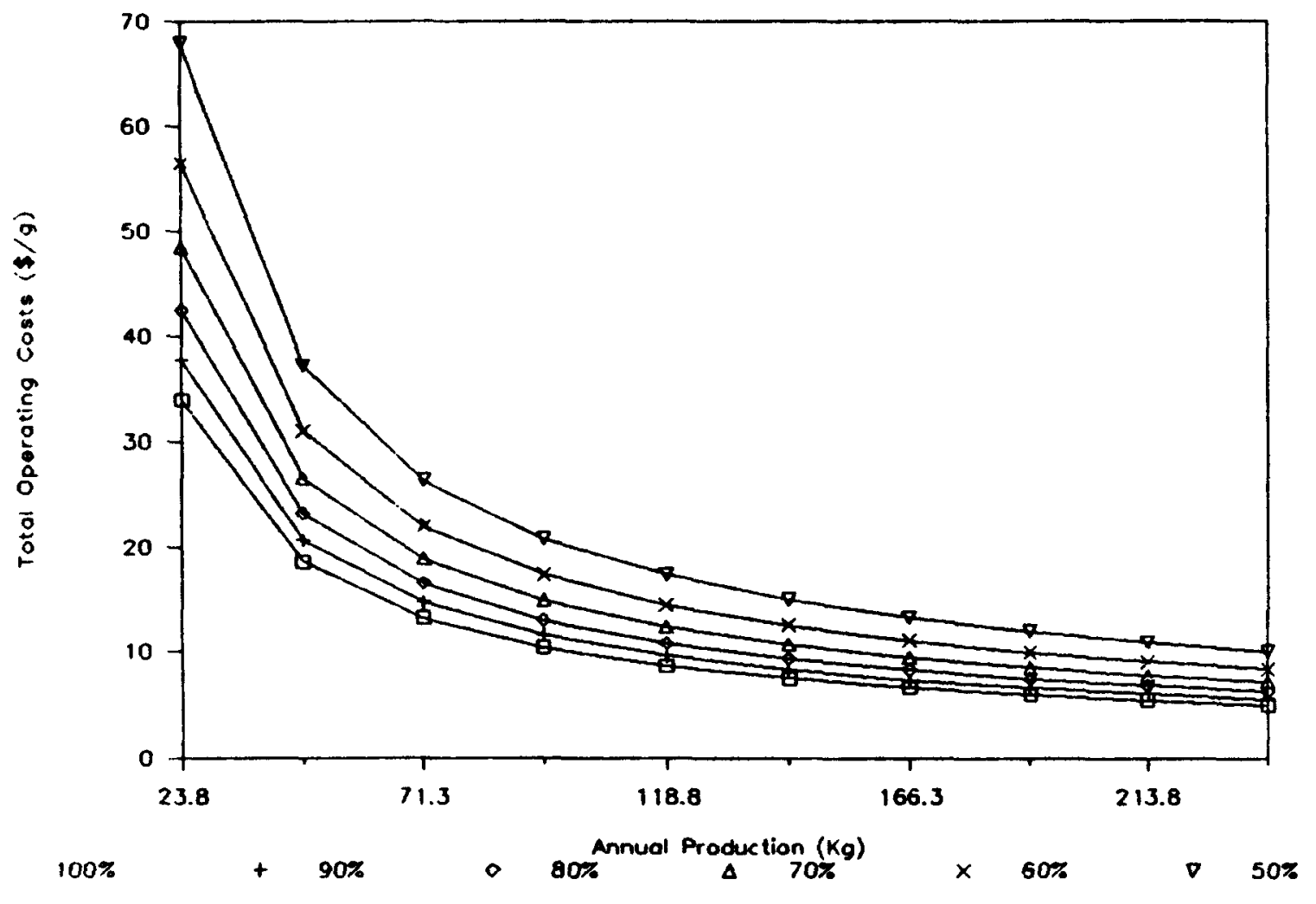

FIGURE 3 - Operating cost versus product acceptability -- recycle facility. 
The operating cost versus product acceptability plots for both virgin and recycle facilities follow an inverse relationship, where the operating cost differences for the range of product acceptabilities essentially "line-out" at batch sizes of $5 \mathrm{~kg}$ (representing $118+\mathrm{kg}$ annual production) and greater. It is, therefore, recommended, to minimize both capital investment and the effect of product variability/acceptability on operating costs, that a production batch size of $5 \mathrm{~kg}$ be selected. This selection assumes that annual production requirements are below the approximately $118 \mathrm{~kg}$ which the process can produce under normal operating conditions.

An interesting result of this economic evaluation is provided in Table 3. For a 100\% acceptable product, total operating costs are lower for the recycle facility than for the virgin facility at production batch sizes greater than $3 \mathrm{~kg}$. These results provide a real economic incentive to recycle the palladium material.

\section{Production Facility Description}

\subsection{Introduction}

The Palladium Production Facility Process

Flow Diagram (Figure 4 and Tables 5-14) depicts the Muddy Water process developed by D. R. Grove and others at Mound. This is a nitric acid-based, batch process (most commercial processes are hydrochloric acid-based) which produces a palladium powder product meeting the low-chlorine specifications required by LANL.

The lirst step of the Muddy Water process involves the dissolution of the palladium sponge (either new, clean sponge in the virgin process or recovered material in the recycle process) in a $70 \%$ nitric acid solution. The initial charge of nitric acid is $5 \mathrm{~L}$ per $1 \mathrm{~kg}$ of sponge. A minute quantity of hydrochloric acid ( $1 \mathrm{~mL}$ per $\mathrm{kg}$ sponge) is also added which behaves as a catalyst to initiate the dissolution process. The digester/reactor is heated to $120+{ }^{\circ} \mathrm{C}$ and agitated to boil down and concentrate the solution to approximately one-half its original volume. The boil-off and dissolving palladium sponge liberates nitric oxide lumes which must be condensed and scrubbed. The final solution of dissolved palladium in nitric acid is termed "redwine" due to its appearance. The desired redwine concentrations are approximately 2.5 molar palladium and 6-8 molar nitric acid. The solution is filtered before transfer to the neutralization step to remove any insolubles (traces of gold and platinum from the sponge material). This step requires approximately $3 \mathrm{hr}$.

In the neutralization step, the redwine is slowly charged to a solution consisting of $29.9 \%$ ammonium hydroxide $(-3.5 \mathrm{~L} / \mathrm{kg} \mathrm{Pd})$, deionized water $(-35 \mathrm{~L} / \mathrm{kg} \mathrm{Pd})$, and glacial acetic acid $(\sim 0.06 \mathrm{~L} / \mathrm{kg} \mathrm{Pd})$. The slow addition of redwine to the neutralization solution (versus adding solution to the redwine) allows for easy formation of the desired $\mathrm{Pd}$ $\left(\mathrm{NH}_{3}\right)_{4}\left(\mathrm{NO}_{3}\right)_{2}$ solution. The addition of neutralization solution to redwine was found to form $\mathrm{Pd}(\mathrm{OH})_{2}$ precipitate, which is undesirable. The final neutralization solution has a $\mathrm{pH}$ of approximately 8.5 and is termed "vinegar" due to its appearance and odor. This processing step is carried out at essentially room temperature with no intentional temperature control. The solution is agitated during the redwine addition and a minimal amount of ammonia vapors evolve (negligible for processing purposes). The neutralized vinegar solution is filtered before transfer to the reduction step to remove traces of iron hydroxide precipitate which form (from the starting sponge material). This step requires approximately $4 \mathrm{hr}$.

The primary reduction step is carried out in a third reactor. The reducing agent ( $88 \%$ formic acid) is added to the vinegar at a rate of $-0.7 \mathrm{~L} / \mathrm{kg} \mathrm{Pd}$. The temperature of this step is carefully controlled at $36^{\circ} \mathrm{C}$ and slight agitation is used while adding the formic acid. Carbon dioxide effervescence is present in a moderate amount, but not to the extent of being a problem. The solution $\mathrm{pH}$ is approximately 

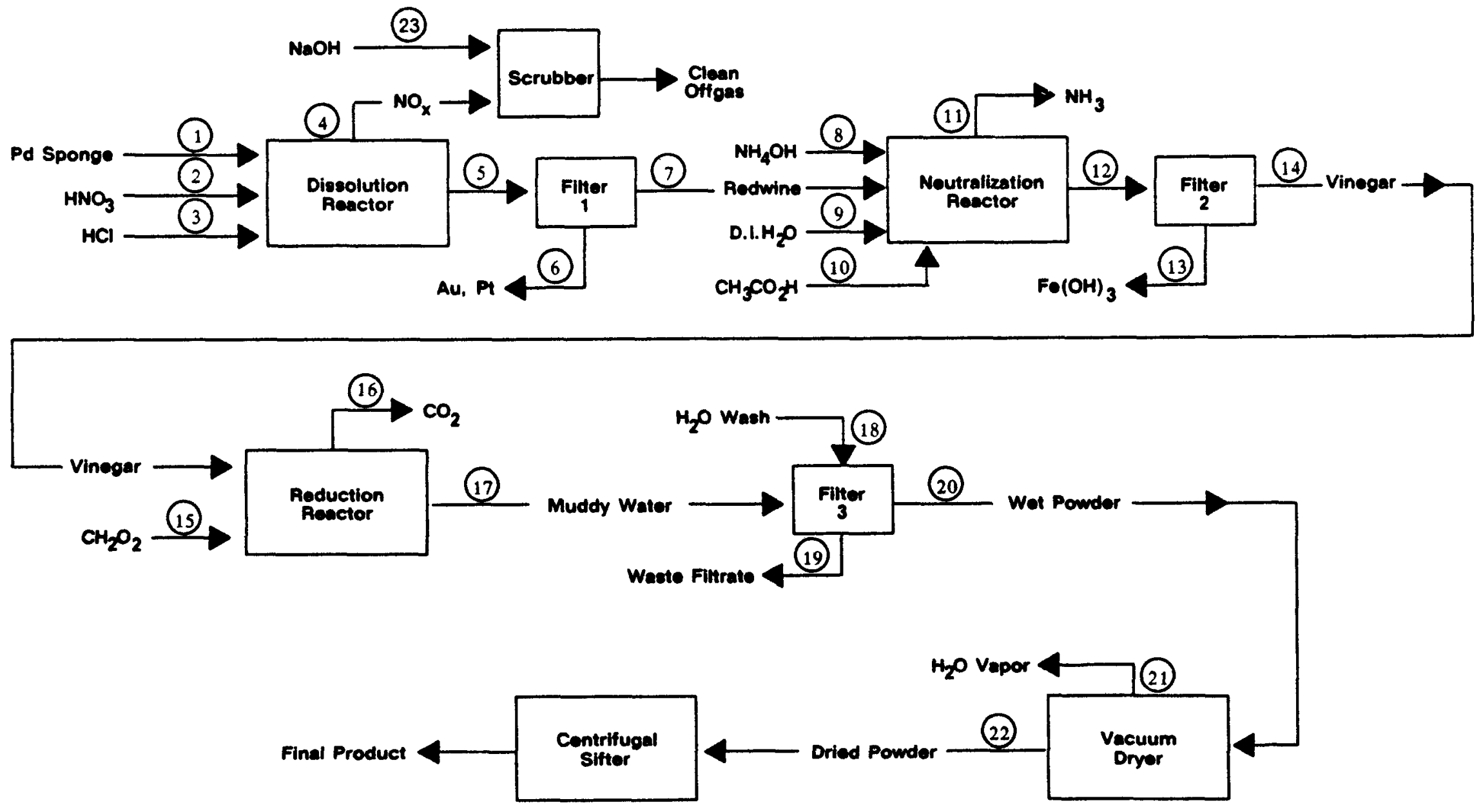

FIGURE 4 - "Muddy Water" palladium processing facility -- process flow diagram. 
3.5 at this stage. As the palladium powder product is generated, the appearance of the reduction solution gradually evolves from a pale yellow color to an olive green and, finally, to a "muddy water" brown. The reduction step may take as long as $8 \mathrm{hr}$ to allow time for complete reduction.

The muddy water solution is then filtered to recover the palladium powder product. The powder is then washed with deionized water at quantities of $-45 \mathrm{~L} / \mathrm{kg}$ Pd. The remaining waste filtrate may be processed through a second reduction step using a strong reducing agent (such as sodium borohydride) to recover the trace concentrations of palladium remaining in solution. This step would be performed in the same reduction reactor as the primary step and under similar operating conditions.

The wet palladium powder resulting after the above filter wash is then placed in a vacuum tray oven at approximately $80^{\circ} \mathrm{C}$ and dried for about $6 \mathrm{hr}$. The dried powder is then run through a centrifugal sifter to break up any clumps. A screen mesh size of 100 is used to recover the final palladium powder product. The total product yield is typically $95+\%$.

\subsection{Process Flow Diagram}

The process flow diagram for the palladium processing facility is provided in Figure 4 . The process flow sheets for production batch sizes from $1 \mathrm{~kg}$ to $10 \mathrm{~kg}$ (in $1-\mathrm{kg}$ increments) are provided in Tables 5 through 14 . This flow diagram applies to both the cold virgin and recycle processes (only hardware and waste treatment requirements differ for the two lacilities).

\section{Total Capital Invest- ment Calculations}

\subsection{Virgin Process Facility}

\subsubsection{Building/Site/Utilities}

Since the facility location is undetermined at this time, several assumptions were required to generate the estimate. For the virgin process, it was assumed that a grass-roots facility would be constructed at Mound at a location within $800 \mathrm{ft}$ of required site utilities, such as low-pressure steam, deionized water, compressed air, and storm drainage tie-ins. Site work required is assumed to include grading, paving, sidewalks, and curbs.

The production facility building is assumed to be a pre-engineered "Butler-type" building based on the plan view sketch illustrated in Figure 5. The building is assumed to contain a chemical storage area, an office area, and miscellaneous laboratory benches, sinks, etc. to support the process. Electrical, HVAC, and sprinkler system installations are also included.

The floor plan layout in Figure 5 is based on the $10-\mathrm{kg}$ production batch size process. The building cost estimates for the 1 - through $9-\mathrm{kg}$ batch sizes are factored from this "full-scale" estimate in the following manner.

General site work, which includes grading, paving, sidewalks, curbs, etc., as well as the utilities installations is considered a fixed cost for all facility sizes, and is estimated at $\$ 102,700$. The remaining costs are considered variable with respect to required floor area. The required floor area for the $10-\mathrm{kg}$ batch size is $1125 \mathrm{ft}^{2}$ at a cost of $\$ 99,300$. This generates a variable cost of $\$ 88.27$ per $\mathrm{ft}^{2}$ of floor area required. It is assumed a $1-\mathrm{kg}$ production facility will require approximately one-half the floor area of the 10-kg facility (because much of the floor area needed for storage, office space, access paths, etc. is fixed). This generates a scaling factor of 0.3. The final equation used for the building estimates is:

$$
\begin{aligned}
& \text { Building/Site/Utilities Cost }= \\
& \$ 102,700+\left(\$ 88.27 \mathrm{ft}^{2}\right)\left(1125 \mathrm{ft}^{2}\right)\left(\frac{\text { Batch Size }}{10 \mathrm{~kg}}\right)^{0.3}
\end{aligned}
$$

Table 1 provides the total costs for building, site work, and utilities at each of the production batch sizes. 


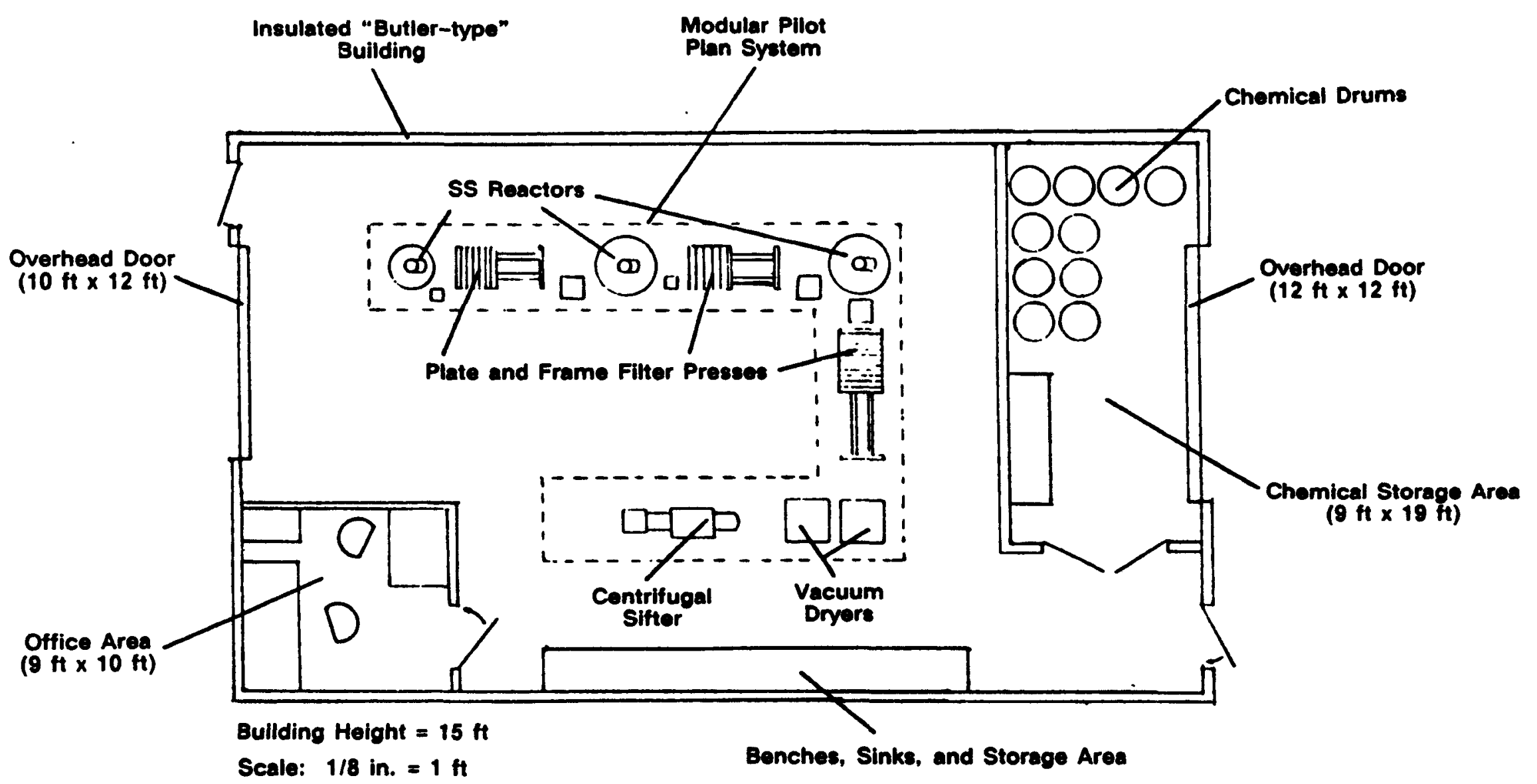

FIGURE 5 - Plan view -- virgin process facility. 
Table I provides the total costs for building, site work, and utilities at each of the production batch sizes.

\subsubsection{Pilot Plant System}

The pilot plant system cost estimate was provided by the Pfaudler Company, based on information we provided on process equipment and working capacity requirements for the $10-\mathrm{kg}$ production batch size. Figure 5 provides a rough sketch of the major process equipment involved. The pilot plant system would be of modular construction and includes the following equipment:

1. A 20-gal stainless steel reactor (digester), including an electric heating mantle, a variable speed drive, explosion-prool electric motor, and an impeller agitator.

2. Two 150-gal stainless steel reactors (neutralization and reduction reactors), including carbon steel jackets, variable speed drive/explosion proof electric motors, and an impeller agitator.

3. A jacketed pipe, stainless steel condenser furnished with all required fittings, flanges, nozzles, couplings and gaskets.

4. Three, pilot-scale, stainless steel plate and frame filler presses, including all required nozzles and hardware.

5. Transfer pumps, Teflon wetted parts, complete with electric molors, base plates, couplings, and coupling guards. Three furnished.

6. One lot of instrumentation consisting of temperature transmitters, temperature indicating controllers, recorders, $\mathrm{pH}$ probes and control valves. Control panel furnished with instruments mounted, piped, and wired. Pressure and temperature gauges also included.

7. One lot of piping, valves, fittings, flanges and piping accessories, stainless steel and
Teflon construction, to interconnect the Pfaudler furnished equipment.

The estimated cost for this $10-\mathrm{kg}$ production batch-size, pilot plant system was $\$ 300,000$. Using the six-tenths factor rule, cost estimates for the remaining batch sizes (listed in Table 1) were generated from the following equation:

$$
\begin{aligned}
& \text { Pilot Plant System Cost }= \\
& \$ 300,000 \times\left(\frac{\text { Batch Size }}{10 \mathrm{~kg}}\right)^{0.8}
\end{aligned}
$$

\subsubsection{Scrubber System}

Quotes from several vendors were provided on a fume scrubbing system to scrub the estimated 20 SCFM flow rate of nitric acid vapors generated in the $10-\mathrm{kg}$ batch size digester reaclor. The packed scrubbers, using 50\% sodium hydroxide solution as the scrubbing medium, were estimated at an average cost of $\$ 13,000$. This cost included a draft hood, duct work, blower fan, $\mathrm{pH}$ control system with metering pumps, and a control panel with all required switches and alarms.

Again, the six-tenths factor rule was applied to estimate the costs for the smaller batch sizes. These costs are provided in Table 1 . The resulting equation is:

$$
\begin{aligned}
& \text { Scrubber System Cost }= \\
& \$ 13,000 \times\left(\frac{\text { Batch Size }}{10 \mathrm{~kg}}\right)^{0.5}
\end{aligned}
$$

\subsubsection{Vacuum Oven}

The average estimated cost quotes for using vacuum tray ovens to dry the wet palladium powder were $\$ 2,800$ for 1 - through $5-\mathrm{kg}$ batch sizes, and $\$ 5,500$ for $6-$ through $10-\mathrm{kg}$ batch sizes.

\subsubsection{Centrifugal Sifter}

The average estimated cost quote for a centrifugal sifter was $\$ 7,200$. This equipment is capable of handling product batch sizes from 1 through $10 \mathrm{~kg}$. 


\subsubsection{Drum Pumps}

Drum pumps are required for transferring the raw material chemicals from their storage drums to the process reactors. Quotes on such pumps are $\$ 500$ each, with the number of pumps increasing with increasing production batch sizes.

\subsubsection{Installation}

The installation cost is estimated at $25 \%$ of purchased equipment cost, which includes all items above. This percentage is based on both text book conventions and similar process installations at Mound. This cost includes overhead.

\subsubsection{Engineering}

Engineering cost is estimated at $25 \%$ of the installed equipment cost, the historical average on processing facility installations at Mound. This cost is also burdened (includes overhead).

\subsubsection{Contingency}

Because of the many uncertainties and unknowns in the production facility at this time, a contingency of $35 \%$ of installed equipment plus engineering costs is used. This is consistent with the order-of-magnitude nature of the cost estimates.

\subsubsection{Project Management}

A project management cost of $5 \%$ of the total fixed capital cost is applied to projects of this scale because of administrative, quality assurance, and reporting requirements mandated by the DOE.

\subsubsection{Working Capital Costs}

Working capital costs are the initial expenses incurred to purchase the raw materials, spare parts, operating supplies, etc. to cover, approximately, the first two production batches. These start-up costs are estimated at $15 \%$ of the fixed capital costs.

\subsection{Recycle Process Facility}

\subsubsection{Room Modifications}

As with the virgin process facility, the location for the recycle process facility is unknown at this time and, thus, several assumptions are made. It is assumed that the recycle process facility will be located in an existing building which is equipped with the utilities, support facilities, and services required for the process. It is assumed that the location will require complete renovation, including HVAC service. The required floor area of $1150 \mathrm{ft}^{2}$ for the 10-kg batch size (determined by the glovebox layout provided below) is used as the basis for the estimate, along with a cost estimate of $\$ 200 / \mathrm{ft}^{2}$ provided by Smith, Stevens, and Young for recent work on a similar lab renovation. A three-tenths factor is again used for scaling the required floor area and resulting cost. The equation is provided below, with the results listed in Table 2 .

$$
\begin{aligned}
& \text { Room Modifications Cost }= \\
& \left(\$ 200 / \mathrm{f}^{2}\right)\left(1150 \mathrm{ft^{2 }}\right)\left(\frac{\text { Batch Size }}{10 \mathrm{~kg}}\right)^{\circ s}
\end{aligned}
$$

\subsubsection{Gloveboxes}

The recycle process facility requires the process equipment to be housed in gloveboxes. The linear feet of gloveboxes required were determined in the following manner: 


\begin{tabular}{lr}
\multicolumn{1}{c}{$\operatorname{Llem(s)}$} & $\begin{array}{c}\text { Glovebox } \\
\text { Required } \\
\text { (fl) }\end{array}$ \\
\cline { 2 - 2 } 3 reactors (3 ft ea) & 9 \\
3 filters (4 ft ea) & 12 \\
4 pumps ( $1 \mathrm{ft} \mathrm{ea)}$ & 4 \\
Condenser & 3 \\
Scrubber & 5 \\
Waste filtrate receiver & 5 \\
Drying ovens & 6 \\
Centri-sifter & 6 \\
TOTAL & 50
\end{tabular}

The configuration and layout of these gloveboxes, as well as the required floor area, are provided in Figure 6.

The gloveboxes purchased equipment costs are estimated at $\$ 6,000 /$ linear $\mathrm{ft}$., based on recent projects. Using a three-tenths factor for required glovebox length at various batch sizes, the following equation was used:

$$
\begin{aligned}
& \text { Glovebox Costs }= \\
& (\$ 6000 / \mathrm{ft})(50 \mathrm{ft})\left(\frac{\text { Batch Size }}{10 \mathrm{~kg}}\right)^{0.3}
\end{aligned}
$$

The resulting costs are provided in Table 2 .

\subsubsection{Glovebox Purge System}

The glovebox purge system is required to maintain an acceptable atmosphere within the glovebox by use of monitors, analyzers, and pressure control devices. This system is essentially the same for all glovebox operations, regardless of size, and is estimated at a cost of $\$ 49,300$. This cost is fixed for all production batch sizes.

\subsubsection{Pilot Plant System}

The pilot plant system for the recycle process is assumed identical to that described in the virgin process, Section 4.1 .2 above. An additional $\$ 3,000$ is added to the $10-\mathrm{kg}$ batch size estimate to include the cost of a $300-\mathrm{gal}$ stainless steel waste filtrate storage tank. The six-tenths factor rule was again applied.

\subsubsection{Scrubber System}

The scrubber system is assumed identical to that described in Section 4.1.3. The same costs apply.

\subsubsection{Vacuum Oven}

This equipment and costs are assumed identical to that described in Section 4.1.4.

\subsubsection{Centrifugal Sifter}

Assumed identical to that described in Section 4.1 .5 .

\subsubsection{Drum Pumps}

Assumed identical to that described in Section 4.1.6.

\subsubsection{Installation}

Installation costs are again estimated at $25 \%$ of purchased equipment costs (includes overhead).

\subsubsection{Engineering}

Engineering costs (including overhead) are estimated at $25 \%$ of installed equipment costs.

\subsubsection{Contingency}

A contingency of $35^{\circ} \%$ of installed equipment plus engineering is used.

\subsubsection{Project Management}

A $5 \%$ of total fixed capital cost is again applied.

\subsubsection{Working Capital Costs}

Fifteen percent of fixed capital costs is applied. 


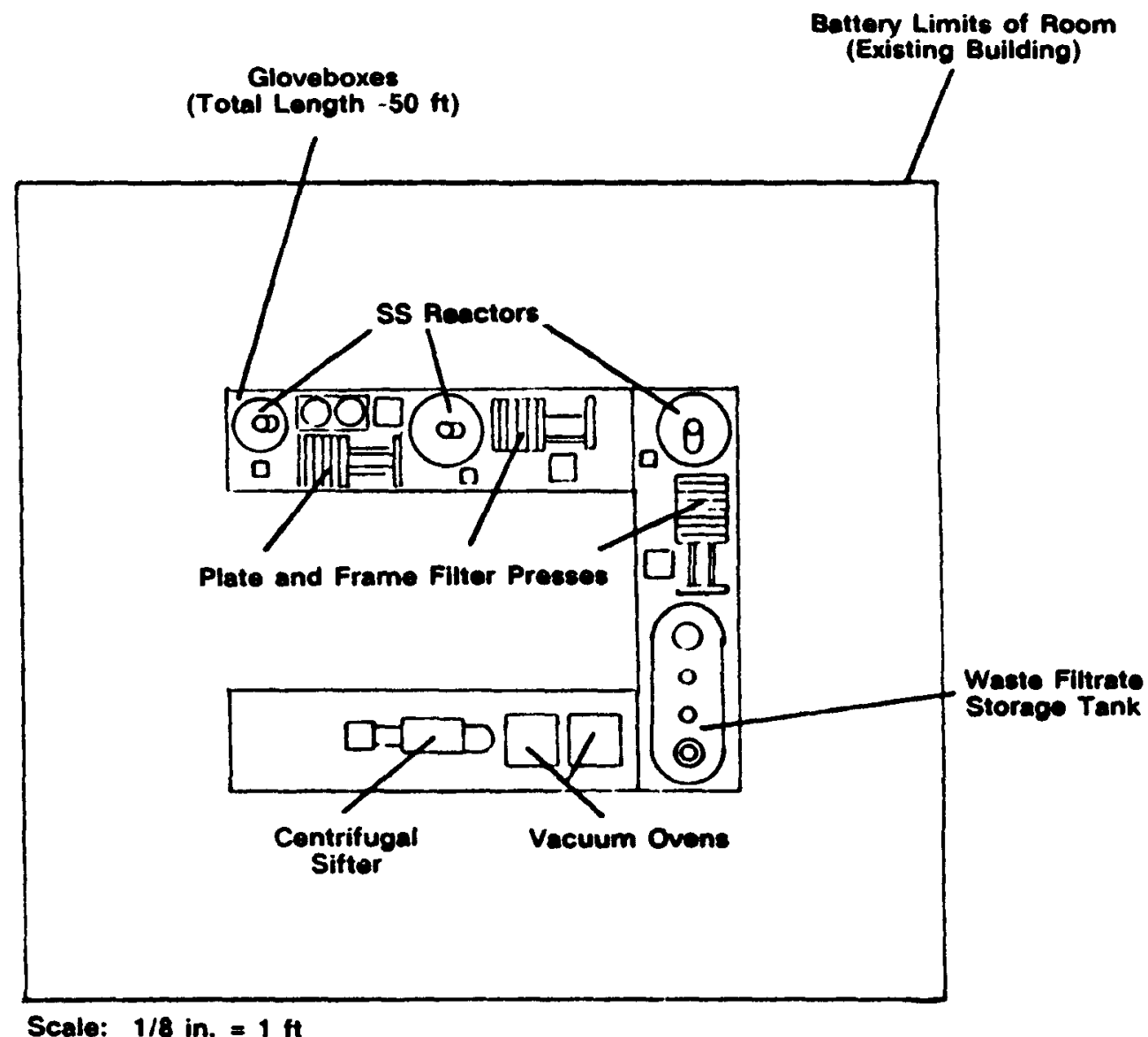

FIGURE 6 - PIan view -- recycle process facility.

\section{Total Operating Cost Calculations}

\subsection{Introduction}

Tables 3 and 4 provide the operating cost results for both the virgin and recycle facilities. As shown in Table 3, a 95\% process yield is assumed for all batch sizes, as well as for both facilities. The Annual Yield results are based on a production rate of 25 batches per year. for all batch sizes. This production rate would allow 2-3 working days for actually manufacturing the product, and 7-8 working days for analytical work to determine the product quality. The analytical results for each batch should be evaluated before proceeding with the next batch. This is the best method of operation because corrections in the manufacturing process can be made, if necessary, to bring the product within specification before proceeding with successive batches. This will minimize operating costs and eliminate the problem of making several batches of unacceptable product before detecting them.

In Table 4, more than 25 batches will be required, as acceptability decreases, to meet the annual product yields provided in Table 3 . For example, at a $50 \%$ product acceptability rate, 50 batches of product would have to be manufactured per year to generate 25 batches of acceplable product. The increasing operating costs in dollars per gram account for this increasing production rate.

The following sections describe the calculations used in determining the itemized operating costs listed in Table 3. 


\subsection{Virgin Process Facility}

\subsubsection{Raw Materials}

Raw material costs include the costs of the original palladium sponge as well as all chemicals used in the manufacturing process. The cost for palladium sponge purchased through the U.S. Dept. of Energy is $\$ 5$ per gram, and constitutes $95 \%$ of the total raw material costs. Quotes on 55-gal drums of the commodity chemicals used in the process were received from several local distributors and an average cost used in the calculations. The drum deposits on the chemicals are a "one-time" cost which are assumed paid in the Working Capital Costs of the Total Capital Investment (Tables 1 and 2).

Chemical requirements on a volume per gram basis were calculated using the process flow sheets. (Tables 5 through 14). From the known "dollars per 55 gallons", and "gallons per gram" requirements, the total cost of the commodity chemicals used were calculated at 27 cents per gram. Thus a total cost of $\$ 5.27$ per gram is generated for raw materials, which is constant at all production batch sizes.

\subsubsection{Analytical}

The analytical costs are essentially the manhours used on the 11 analyses required to determine product quality. This manpower is estimated at 6.5 man-days per batch, independent of batch size. The total estimated analytical cost per batch, including overhead costs, is approximately $\$ 5,700$. As a fixed cost independent of batch size, the resulting dollars per gram for analytical costs drop considerably as the batch sizes are increased. Thus, the larger the batch size, the more economical the analytical process. Analytical costs are shown to be significant in the smaller batch sizes (Table 3 ), but are greatly reduced in the larger batches.
The quantity of product consumed and scrapped during the analytical process is less than 5 grams per batch, independent of batch size. This loss is part of the $5^{\circ} \%$ loss described in the production process (i.e., 95\% yield per batch).

\subsubsection{Labor}

The labor costs for operating the manufacturing process are estimated at one man-year of technician time and 0.2 man-year of engineering time for the $1-\mathrm{kg}$ batch size process. This 1.2 man-year includes research and development, and overhead costs. The resulting burdened labor cost for the 1-kg batch size is approximately $\$ 222,400$ per year. A conventional scale-up factor of 0.2 is used for labor requirements at increasing batch sizes, thus labor costs are not assumed fixed and independent of batch size. However, as Table 3 illustrates, labor costs also drop significantly as batch size is increased.

\subsubsection{Utilities}

The utilities costs are the estimated energy requirements for the various production batch sizes, in kilowatt-hours ( $\mathrm{kWhr}$ ) per batch. A portion of these requirements are assumed fixed, such as building utilities, monitors and instrumentation, and single-sized equipment. The remaining energy requirements increase proportionally with increasing equipment sizes (i.e. reactor agitators, pumps, fume scrubbers, reactor heaters, etc.). The total $\mathrm{kWhr}$ per batch range from approximately 2,000 for a $1-\mathrm{kg}$ batch size to 3,100 for a 10-kg batch size. The energy cost used in the calculations is 5 cents per $\mathrm{k} W \mathrm{Wh}$.

\subsubsection{Maintenance}

A conventional estimate of annual maintenance cost at 10\% of Fixed Capital Costs (Tables 1 and 2) is used and divided by the annual yield to generate the cost on a dollars per gram basis. 


\subsubsection{Operating Supplies}

Again, a conventional estimate of $15 \%$ of Maintenance costs is used to cover the costs of operating supplies on a dollars per gram basis.

\subsection{Recycle Process Facility}

\subsubsection{Raw Materials}

The costs for raw materials is calculated in the same manner as for the virgin facility, except that the palladium sponge cost of $\$ 5$ per gram is omitted. In the recycle process, the palladium source material has already been paid for in the initial manufacturing process, thus costing it here again would result in double-counting. The elimination of the palladium sponge cost significantly reduces the overall, total operating costs for the recycle process. As Table 3 illustrates, for a product that is $100 \%$ acceptable, the total operating costs are actually lower for the recycle facility than for the virgin facility at batch sizes greater than $3 \mathrm{~kg}$. This is an attractive incentive for recycling the palladium product, regardless of its source.

\subsubsection{Analytical}

Experience in analyses of similar materials shows that $300^{\circ} \%$ more manpower will be required to generate the analytical results for the recycle product. Thus analytical costs are tripled at all production batch sizes.

\subsubsection{Labor}

Labor costs are increased by $20 \%$ over the virgin process estimate to account for the differing facilities and hardware, and additional Health Physics support which will be required on occassion.

\subsubsection{Utilities}

The utilities costs have likewise been increased by $20 \%$ over the virgin process to account for differing $H V A C$ requirements and additional instrumentation requirements.

\subsubsection{Maintenance}

Identical to the virgin process, annual maintenance costs are estimated at $10^{\circ} \%$ of the Fixed Capital Costs.

\subsubsection{Operating Supplies}

Operating supplies are estimated at $15 \%$ of the maintenance costs (identical to the virgin process estimate).

\subsubsection{Waste Disposal}

Unlike the virgin process, where all waste streams generated can be sent directly to the sanitary sewer, the recycle process requires special treatment of the waste streams. This cost is estimated at $\$ 10$ per gallon of waste generated. The cost includes drumming, processing, cement/filler materials, shipment. burial, and overhead costs. Using the process flow sheets of Tables 5 through 14 to determine the total waste generated, a waste disposal cost of 25 cents per gram is calculated. 
Appendix A 
THIS PAGE IS BLANK 
TABLE 1

Total Capital Investment -- Virgin Facility (Thousands of Dollars)

\begin{tabular}{|c|c|c|c|c|c|c|c|c|c|c|}
\hline & & & & Productio & n Batch S & ize (Kg) & & & & \\
\hline & 1.0 & 2.0 & 3.0 & 4.0 & 5.0 & 6.0 & 7.0 & 8.0 & 9.0 & 10.0 \\
\hline & $===== \pm=$ & $======$ & $=======$ & $=======$ & $======$ & $=======$ & $=======$ & $===== \pm=$ & $======$ & $===== \pm=$ \\
\hline Building/Site/Utilities & 152.5 & 164.0 & 171.9 & 178.1 & 183.4 & 187.9 & 191.9 & 195.6 & 198.9 & 202.0 \\
\hline Pilot Plant System & 75.4 & 114.2 & 145.7 & 173.1 & 197.9 & 220.8 & 242.2 & 262.4 & 281.6 & 300.0 \\
\hline Scrubber System & 3.3 & 4.9 & 6.3 & 7.5 & 8.6 & 9.6 & 10.5 & 11.4 & 12.2 & 13.0 \\
\hline Vacuum Oven & 2.8 & 2.8 & 2.8 & 2.8 & 2.8 & 5.5 & 5.5 & 5.5 & 5.5 & 5.5 \\
\hline Centrifugal sifter & 7.2 & 7.2 & 7.2 & 7.2 & 7.2 & 7.2 & 7.2 & 7.2 & 7.2 & 7.2 \\
\hline Drum Pumps & 1.0 & 1.5 & 1.5 & 1.5 & 2.0 & 2.0 & 2.0 & 2.5 & 2.5 & 2.5 \\
\hline Installation & 60.5 & 73.7 & 83.8 & 92.6 & 100.5 & 108.2 & 114.8 & 121.1 & 127.0 & 132.6 \\
\hline Engineering & 75.7 & 92.1 & 104.8 & 115.7 & 125.6 & 135.3 & 143.5 & 151.4 & 158.7 & 165.7 \\
\hline Cont ingency & 132.4 & 161.1 & 183.4 & 202.5 & 219.8 & 236.8 & 251.2 & 265.0 & 277.8 & 290.0 \\
\hline & $\ldots \ldots$ & -...... & - $\ldots$. & $\ldots \ldots$ & - $\ldots+\cdots$ & - n..... & $\cdots+$ & -....... & -...... & $\cdots$ \\
\hline Fixed Capital Costs & 510.7 & 621.5 & 707.5 & 781.0 & 847.7 & 913.3 & 968.9 & 1022.1 & 1071.4 & 1118.4 \\
\hline Project Management & 25.5 & 31.1 & 35.4 & 39.1 & 42.4 & 45.7 & 48.4 & 51.1 & 53.6 & 55.9 \\
\hline Working Capital Costs & $======$ & $==83.2$ & $======$ & $======$ & $======$ & $======$ & $======$ & $\begin{array}{r}153.3 \\
======\end{array}$ & $======$ & $======$ \\
\hline Total Capital Investme & 612.8 & 745.8 & 849.0 & 937.2 & 1017.2 & 1096.0 & 1162.7 & 1226.5 & 1285.7 & 1342.1 \\
\hline
\end{tabular}


TABLE 2

\begin{tabular}{|c|c|c|c|c|c|c|c|c|c|c|}
\hline & \multicolumn{10}{|c|}{ Production Batch Size (Kg) } \\
\hline & 1.0 & 2.0 & 3.0 & 4.0 & 5.0 & 6.0 & 7.0 & 8.0 & 9.0 & 10.0 \\
\hline & $==x=x=0$ & $==x===8$ & $=x====8$ & $==x=x=2$ & $z=====x$ & $=x=x=x=$ & $==x= \pm=8$ & $=x==x=$ & $=x= \pm==0$ & $=x= \pm==0$ \\
\hline Room Modifications & 115.3 & 141.9 & 160.3 & 174.7 & 186.8 & 197.3 & 206.7 & 215.1 & 222.8 & 230.0 \\
\hline Gloveboxes & 150.4 & 185.1 & 209.1 & 227.9 & 243.7 & 257.4 & 269.6 & 280.6 & 290.7 & 300.0 \\
\hline Glovebox Purge System & 49.3 & 49.3 & 49.3 & 49.3 & 49.3 & 49.3 & 49.3 & 49.3 & 49.3 & 49.3 \\
\hline Pilot Plant Systen & 76.1 & 115.4 & 147.1 & 174.9 & 199.9 & 223.0 & 244.6 & 265.0 & 284.4 & 303.0 \\
\hline Scrubber System & 3.3 & 4.9 & 6.3 & 7.5 & 8.6 & 9.6 & 10.5 & 11.4 & 12.2 & 13.0 \\
\hline Vacuum Oven & 2.8 & 2.8 & 2.8 & 2.8 & 2.8 & 5.5 & 5.5 & 5.5 & 5.5 & 5.5 \\
\hline Centrifugal sifter & 7.2 & 7.2 & 7.2 & 7.2 & 7.2 & 7.2 & 7.2 & 7.2 & 7.2 & 7.2 \\
\hline Drum Pumps & 1.0 & 1.5 & 1.5 & 1.5 & 2.0 & 2.0 & 2.0 & 2.5 & 2.5 & 2.5 \\
\hline Installation & 101.3 & 127.0 & 145.9 & 161.4 & 175.1 & 187.8 & 198.8 & 209.1 & 218.7 & 227.6 \\
\hline Engineering & 126.7 & 158.8 & 182.4 & 201.8 & 218.8 & 234.8 & 248.5 & 261.4 & 273.3 & 284.5 \\
\hline Cont ingency & 221.7 & 277.9 & 319.1 & 353.2 & 383.0 & 410.9 & 435.0 & 457.5 & 478.3 & 497.9 \\
\hline Fixed Capital Costs & 854.9 & 1071.9 & 1231.0 & 1362.2 & 1477.1 & 1584.7 & 1677.7 & 1764.7 & 1845.0 & 1920.6 \\
\hline Project Management & 42.7 & 53.6 & 61.5 & 68.1 & 73.9 & 79.2 & 83.9 & 88.2 & 92.2 & 96.0 \\
\hline Working Capital Costs & $\begin{aligned} 128.2 \\
== \pm====\end{aligned}$ & $\begin{array}{r}160.8 \\
===== \pm=\end{array}$ & $\begin{array}{r}184.6 \\
=x=x==E\end{array}$ & $\begin{array}{r}204.3 \\
=====x=\end{array}$ & $\begin{array}{r}221.6 \\
==x====\end{array}$ & $\begin{array}{r}237.7 \\
=== \pm===\end{array}$ & $\begin{array}{r}251.6 \\
y=z== \pm==\end{array}$ & $\begin{aligned} & 264.7 \\
== & =====\end{aligned}$ & $\begin{array}{r}276.7 \\
====-=\end{array}$ & $\begin{aligned} & 288.1 \\
&====x==\end{aligned}$ \\
\hline Total Capital Investm & 1025.9 & 1286.2 & 1477.2 & 1634.6 & 1772.6 & 1901.7 & 2013.2 & 2117.6 & 2214.0 & 2304.7 \\
\hline
\end{tabular}


TABLE 3

(100x Product Acceptability)

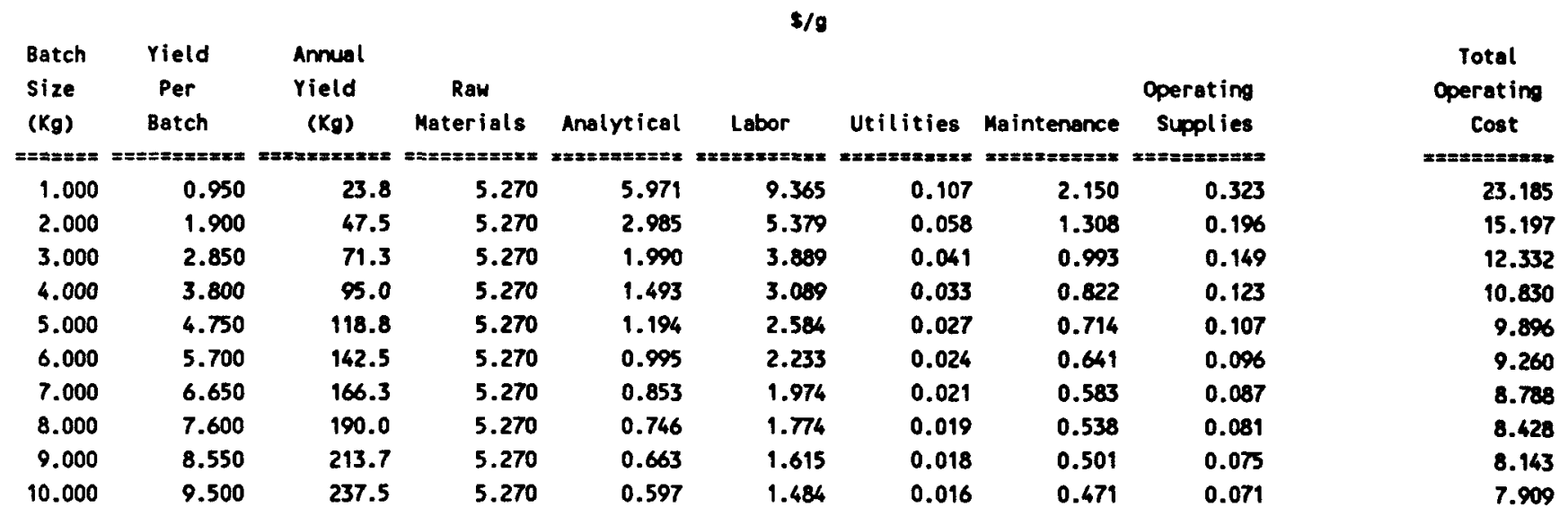

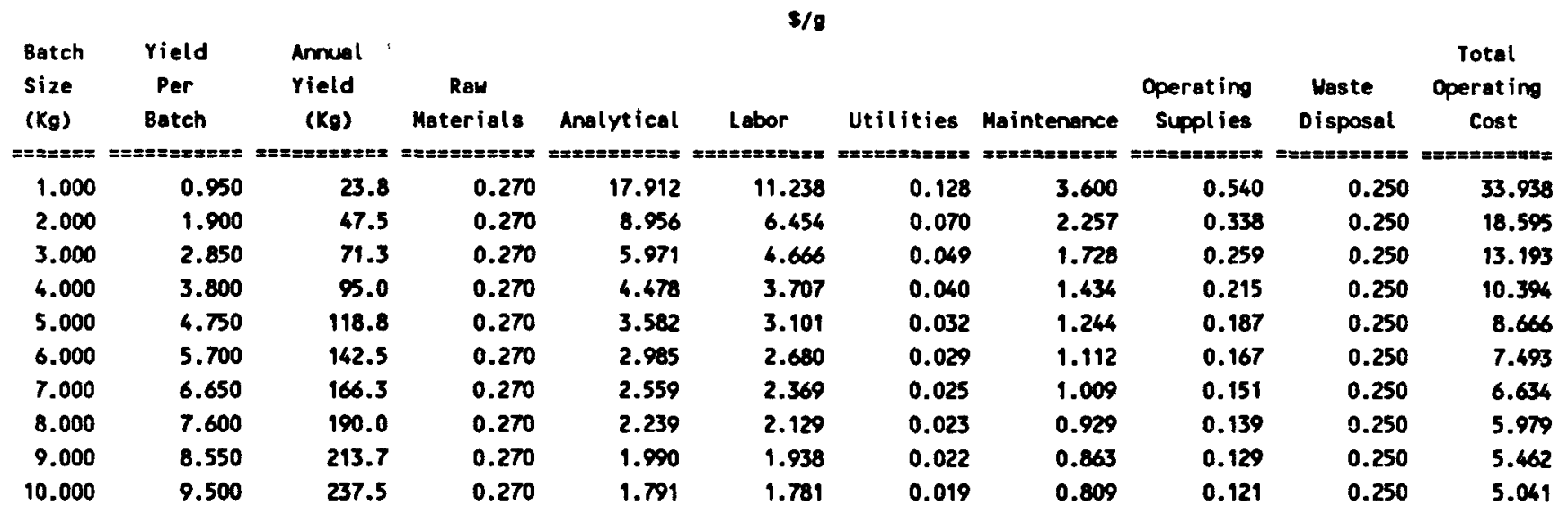


TABLE 4

Operating Costs vs Product Acceptability

- Virgin facility:

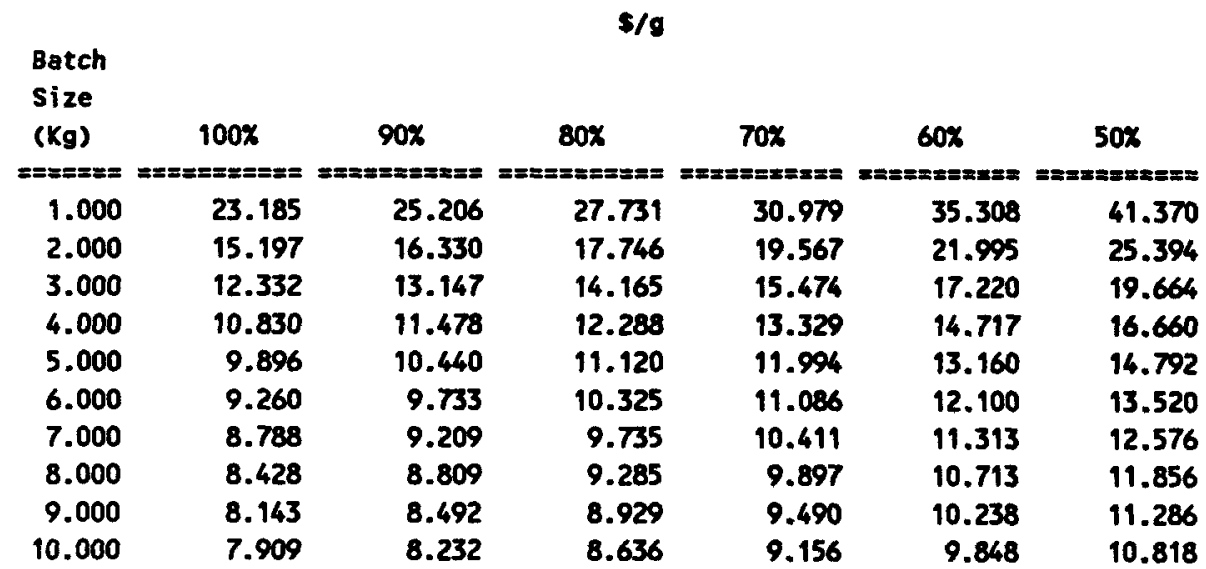

- Recycle Facility:

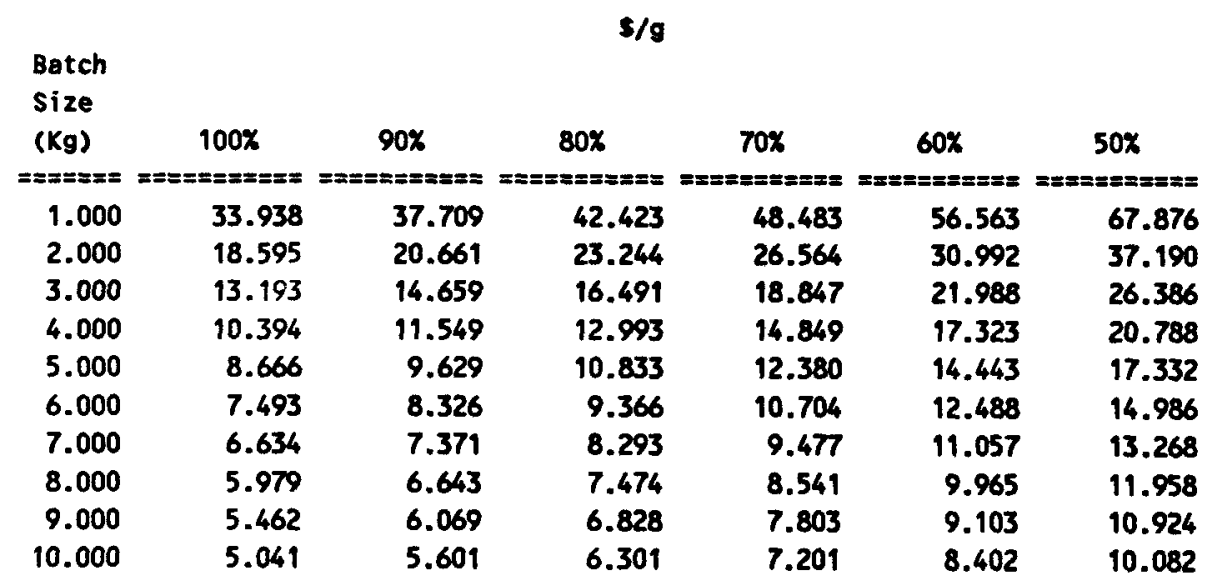


TABLE 5

Palladium Processing Facility flow Sheet $1.0 \mathrm{Kg}$ Production Batch size

\begin{tabular}{cl} 
Stream No. & \multicolumn{1}{c}{$\begin{array}{c}\text { Description } \\
==========\end{array}$} \\
1 & Palladium Sponge \\
2 & $69.9 \%$ Nitric Acid \\
3 & $37.2 \%$ Hydrochloric Acid \\
4 & Nitric Oxide \\
5 & Unfiltered Redwine \\
6 & Gold/Platinum \\
7 & Redwine \\
8 & $29.9 \%$ Ammonium Hydroxide \\
9 & Deionized Hater \\
10 & $100 \%$ Acetic Acid \\
11 & Ammonia Vapors \\
12 & Unfiltered Vinegar \\
13 & Iron Hydroxide \\
14 & Vinegar \\
15 & 88\% Formic Acid \\
16 & Carbon Dioxide \\
17 & Unfiltered Muddy Water \\
18 & Deionized Water \\
19 & Waste Filtrate \\
20 & Wet Palladium Powder \\
21 & Water Vapor \\
22 & Dry Palladium Powder \\
23 & 50.0\% Sodium Hydroxide
\end{tabular}

\begin{tabular}{|c|c|c|c|c|}
\hline $\begin{array}{l}\text { Mass (Kg) } \\
========\end{array}$ & $\begin{array}{l}\text { Volume (l) } \\
=========\end{array}$ & $\begin{array}{l}\text { Phase } \\
=====\end{array}$ & $\begin{array}{l}\text { Temp. (C) } \\
========\end{array}$ & $\begin{array}{l}\text { Pres. (Atm) } \\
==========\end{array}$ \\
\hline 1.000 & 0.167 & s & 123.0 & 1.00 \\
\hline 7.050 & 5.000 & l & 123.0 & 1.00 \\
\hline 0.001 & 0.001 & I & 123.0 & 1.00 \\
\hline 3.525 & $3,204.814$ & g & 123.0 & 1.00 \\
\hline 4.525 & 2.584 & l & 60.0 & 1.00 \\
\hline 0.005 & 0.000 & $\mathbf{s}$ & 60.0 & 1.00 \\
\hline 4.520 & 2.583 & $\ell$ & 20.0 & 1.00 \\
\hline 3.230 & 3.589 & 1 & 20.0 & 1.00 \\
\hline 35.885 & 35.885 & 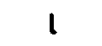 & 20.0 & 1.00 \\
\hline 0.063 & 0.060 & l & 20.0 & 1.00 \\
\hline nil & nil & $\mathbf{g}$ & 20.0 & 1.00 \\
\hline 43.698 & 42.117 & i & 20.0 & 1.00 \\
\hline 0.022 & 0.004 & $\mathbf{s}$ & 20.0 & 1.00 \\
\hline 43.676 & 42.113 & $\mathbf{l}$ & 36.0 & 1.00 \\
\hline 0.847 & 0.718 & l & 36.0 & 1.00 \\
\hline 0.810 & 3.208 & $\mathbf{g}$ & 36.0 & 1.00 \\
\hline 44.523 & 42.830 & $\mathrm{~s} / \mathrm{l}$ & 36.0 & 1.00 \\
\hline 45.000 & 45.000 & $\mathrm{l}$ & 20.0 & 1.00 \\
\hline 88.098 & 86.880 & 1 & 20.0 & 1.00 \\
\hline 1.425 & 0.950 & $s / l$ & 20.0 & 1.00 \\
\hline 0.475 & 0.475 & $\mathbf{g}$ & 80.0 & 1.00 \\
\hline 0.950 & 0.475 & $\mathbf{g}$ & 80.0 & 1.00 \\
\hline 4.476 & 4.879 & $\mathrm{l}$ & 25.0 & 1.00 \\
\hline
\end{tabular}


TABLE 6

Palladium Processing Facility flow sheet

2.0 Kg Production Batch size

\begin{tabular}{|c|c|}
\hline $\begin{array}{l}\text { Stream No. } \\
========\end{array}$ & $\begin{array}{l}\text { Description } \\
===\end{array}$ \\
\hline 1 & Palladium Sponge \\
\hline 2 & $69.9 \%$ Nitric Acid \\
\hline 3 & 37.2\% Hydrochloric Acid \\
\hline 4 & Nitric Oxide \\
\hline 5 & Unfiltered Redwine \\
\hline 6 & Gold/Plat inmm \\
\hline 7 & Reduine \\
\hline 8 & 29.9x Ammonium Hydroxide \\
\hline 9 & Deionized Water \\
\hline 10 & $100 \%$ Acetic Acid \\
\hline 11 & Ammonia Vapors \\
\hline 12 & Unfiltered Vinegar \\
\hline 13 & Iron Hydroxide \\
\hline 14 & Vinegar \\
\hline 15 & $88 \%$ Formic Acid \\
\hline 16 & Carbon Dioxide \\
\hline 17 & Unfiltered Muddy Water \\
\hline 18 & Deionized Water \\
\hline 19 & Waste Filtrate \\
\hline 20 & Wet Palladium Pouder \\
\hline 21 & Water Vapor \\
\hline 22 & Dry Palladiun Pouder \\
\hline 23 & 50.0\% Sodium Hydroxide \\
\hline
\end{tabular}

Mass $(\mathrm{Kg})$
$==x=x==x=$
2.000
14.100
0.001
7.051
9.051
0.010
9.061
6.459
71.770
0.126
nil
87.396
0.044
87.352
1.694
1.619
89.046
90.000
176.196
2.850
0.950
1.900
8.952

Volune (1)
s=x=ex=1=:

0.333
10.000
0.001
$6,409.627$
5.167
0.001
5.167
7.177
71.770
0.120
$n 11$
84.234
0.009
84.225
1.435
6.416
85.661
90.000
173.761
1.900
0.950
0.950
9.757

Phase Temp

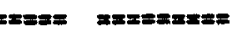

Pres. (Atm)

$x=z===x==x=$

8
1
1
1
8
1
1
1
1
9
1
5
1
1
9
$8 / 1$
1
1
$8 / 1$
9
9
1

123.0

1.00

123.0

123.0

123.0

60.0

60.0

20.0

20.0

20.0

20.0

20.0

20.0

20.0

36.0

36.0

36.0

36.0

20.0

20.0

20.0

80.0

80.0

25.0
1.00

1.00

1.00

1.00

1.00

1.00

1.00

1.00

1.00

1.00

1.00

1.00

1.00

1.00

1.00

1.00

1.00

1.00

1.00

1.00

1.00

1.00 
TABLE 7

Palladium Processing Facility Flow Sheet

$3.0 \mathrm{~kg}$ Production Batch Size

\begin{tabular}{cl} 
Stream No. & \multicolumn{1}{c}{$\begin{array}{c}\text { Description } \\
==========\end{array}$} \\
1 & Palladium Sponge \\
2 & $69.9 \%$ Nitric Acid \\
3 & $37.2 \%$ Hydrochloric Acid \\
4 & Nitric Oxide \\
5 & Unfiltered Redwine \\
6 & Gold/Platinum \\
7 & Redwine \\
8 & $29.9 \%$ Ammonium Hydroxide \\
9 & Deionized Hater \\
10 & $100 \%$ Acetic Acid \\
11 & Ammonia Vapors \\
12 & Unfil tered Vinegar \\
13 & Iron Hydroxide \\
14 & Vinegar \\
15 & 88\% Formic Acid \\
16 & Carbon Dioxide \\
17 & Unfil tered Muddy Water \\
18 & Deionized Water \\
19 & Waste Filtrate \\
20 & Wet Palladium Powder \\
21 & Water Vapor \\
22 & Dry Palladium Powder \\
23 & 50.0\% Sodium Hydroxide
\end{tabular}

\begin{tabular}{|c|c|c|c|c|}
\hline $\begin{array}{l}\text { Mass }(\mathrm{Kg}) \\
========\end{array}$ & $\begin{array}{l}\text { Volume (l) } \\
=========\end{array}$ & $\begin{array}{l}\text { Phase } \\
=====\end{array}$ & $\begin{array}{l}\text { Temp. (C) } \\
========\end{array}$ & $\begin{array}{l}\text { Pres. (Atm) } \\
==========\end{array}$ \\
\hline 3.000 & 0.500 & $\mathbf{s}$ & 123.0 & 1.00 \\
\hline 21.150 & 15.000 & 1 & 123.0 & 1.00 \\
\hline 0.002 & 0.002 & 1 & 123.0 & 1.00 \\
\hline 10.576 & $9,614.441$ & $\mathbf{g}$ & 123.0 & 1.00 \\
\hline 13.576 & 7.751 & i & 60.0 & 1.00 \\
\hline 0.015 & 0.001 & $\mathbf{s}$ & 60.0 & 1.00 \\
\hline 13.561 & 7.750 & 1 & 20.0 & 1.00 \\
\hline 9.689 & 10.766 & 1 & 20.0 & 1.00 \\
\hline 107.656 & 107.656 & $l$ & 20.0 & 1.00 \\
\hline 0.188 & 0.179 & l & 20.0 & 1.00 \\
\hline nil & nil & $\mathbf{g}$ & 20.0 & 1.00 \\
\hline 131.094 & 126.350 & 1 & 20.0 & 1.00 \\
\hline 0.066 & 0.013 & $\mathbf{s}$ & 20.0 & 1.00 \\
\hline 131.028 & 126.338 & 1 & 36.0 & 1.00 \\
\hline 2.541 & 2.153 & 1 & 36.0 & 1.00 \\
\hline 2.429 & 9.624 & $\mathbf{g}$ & 36.0 & 1.00 \\
\hline 133.569 & 128.491 & $s / l$ & 36.0 & 1.00 \\
\hline 135.000 & 135.000 & 1 & 20.0 & 1.00 \\
\hline 264.294 & 260.641 & 1 & 20.0 & 1.00 \\
\hline 4.275 & 2.850 & s/l & 20.0 & 1.00 \\
\hline 1.425 & 1.425 & $\mathbf{g}$ & 80.0 & 1.00 \\
\hline 2.850 & 1.425 & $\mathbf{g}$ & 80.0 & 1.00 \\
\hline 13.428 & 14. & 1 & 25.0 & 1.00 \\
\hline
\end{tabular}


TABLE 8

Palladium Processing Facility flow sheet $4.0 \mathrm{Kg}$ Production Batch Size

\begin{tabular}{|c|c|c|c|c|c|c|}
\hline $\begin{array}{l}\text { Strean No. } \\
=========\end{array}$ & $\begin{array}{l}\text { Description } \\
==\geq x=\geq x=2=\end{array}$ & $\begin{array}{l}\text { Mass (Kg) } \\
== \pm z===x=\end{array}$ & 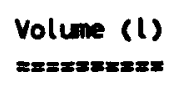 & $\begin{array}{l}\text { Phase } \\
x==x=\end{array}$ & $\begin{array}{l}\text { Temp. (C) } \\
== \pm= \pm x==2\end{array}$ & $\begin{array}{l}\text { Pres. (Atm) } \\
========== \pm\end{array}$ \\
\hline 1 & Palladiun Sponge & 4.000 & 0.667 & 8 & 123.0 & 1.00 \\
\hline 2 & 69.9\% Nitric Acid & 28.200 & 20.000 & 1 & 123.0 & 1.00 \\
\hline 3 & 37.2\% Hydrochloric Acid & 0.002 & 0.002 & $\mathbf{l}$ & 123.0 & 1.00 \\
\hline 4 & Nitric Oxide & 14.101 & $12,819.255$ & 9 & 123.0 & 1.00 \\
\hline 5 & Unfiltered Redwine & 18.101 & 10.334 & i & 60.0 & 1.00 \\
\hline 6 & Gold/Platinum & 0.020 & 0.001 & 8 & 60.0 & 1.00 \\
\hline 7 & Redwine & 18.081 & 10.333 & $\mathbf{l}$ & 20.0 & 1.00 \\
\hline 8 & $29.9 x$ Ammonium Hydroxide & 12.919 & 14.354 & 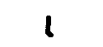 & 20.0 & 1.00 \\
\hline 9 & Deionized Water & 143.541 & 143.561 & $\mathbf{l}$ & 20.0 & 1.00 \\
\hline 10 & $100 x$ Acetic Acid & 0.251 & 0.239 & I & 20.0 & 1.00 \\
\hline 11 & Ammonis Vapors & nil & nil & g & 20.0 & 1.00 \\
\hline 12 & Unfiltered Vinegar & 174.792 & 168.467 & l & 20.0 & 1.00 \\
\hline 13 & Iron Hydroxide & 0.087 & 0.017 & 8 & 20.0 & 1.00 \\
\hline 14 & Vinegar & 174.704 & 168.450 & i & 36.0 & 1.00 \\
\hline 15 & $88 \%$ Formic Acid & 3.388 & 2.871 & $\mathbf{l}$ & 36.0 & 1.00 \\
\hline 16 & Carbon Dioxide & 3.239 & 12.832 & $\mathbf{g}$ & 36.0 & 1.00 \\
\hline 17 & Unfiltered Muddy Water & 178.092 & 171.321 & s/l & 36.0 & 1.00 \\
\hline 18 & Deionized Water & 180.000 & 180.000 & $\mathbf{l}$ & 20.0 & 1.00 \\
\hline 19 & Waste Filtrate & 352.392 & 347.521 & 1 & 20.0 & 1.00 \\
\hline 20 & Wet Palladium Pouder & 5.700 & 3.800 & s/l & 20.0 & 1.00 \\
\hline 21 & Water Vapor & 1.900 & 1.900 & $\mathbf{g}$ & 80.0 & 1.00 \\
\hline 22 & Dry Palladium Pouder & 3.800 & 1.900 & 9 & 80.0 & 1.00 \\
\hline 23 & 50.0\% sodium Hydroxide & 17.904 & 19.514 & $i$ & 25.0 & 1.00 \\
\hline
\end{tabular}


TABLE 9

Palladium Processing Facility Flow Sheet

$5.0 \mathrm{~kg}$ Production Batch size

\begin{tabular}{rl} 
Stream No. & \multicolumn{1}{c}{$\begin{array}{c}\text { Description } \\
==========\end{array}$} \\
1 & Palladiun Sponge \\
2 & $69.9 \%$ Nitric Acid \\
3 & $37.2 \%$ Hydrochloric Acid \\
4 & Nitric Oxide \\
5 & Unfiltered Redwine \\
6 & Gold/Plat inum \\
7 & Redwine \\
8 & $29.9 \%$ Ammonium Hydroxide \\
9 & Deionized Water \\
10 & $100 \%$ Acet ic Acid \\
11 & Ammonia Vapors \\
12 & Unfiltered Vinegar \\
13 & Iron Hydroxide \\
14 & Vinegar \\
15 & $88 \%$ Formic Acid \\
16 & Carbon Dioxide \\
17 & Unfiltered Muddy Water \\
18 & Deionized Water \\
19 & Haste Filtrate \\
20 & Het Palladium Powder \\
21 & Hater Vapor \\
22 & Dry Palladium Powder \\
23 & 50.0\% Sodium Hydroxide
\end{tabular}

Mass $(\mathrm{Kg})$
$=======$
5.000
35.250
0.003
17.626
22.626
0.025
22.601
16.148
179.426
0.314
$n i 1$
218.490
0.109
218.380
4.234
4.049
222.615
225.000
440.490
7.125
2.375
4.750
22.380

Volume $(l)$
$=======$
0.833
25.000
0.003
$16,024.068$
12.918
0.001
12.917
17.943
179.426
0.299
$n i 1$
210.584
0.021
210.563
3.589
16.040
214.151
225.000
434.401
4.750
2.375
2.375
24.393

\begin{tabular}{|c|c|c|}
\hline $\begin{array}{l}\text { Phase } \\
=====\end{array}$ & $\begin{array}{l}\text { Temp. (C) } \\
=========\end{array}$ & $\begin{array}{l}\text { Pres. (Atm) } \\
==========\end{array}$ \\
\hline $\mathbf{s}$ & 123.0 & 1.00 \\
\hline 1 & 123.0 & 1.00 \\
\hline l & 123.0 & 1.00 \\
\hline 9 & 123.0 & 1.00 \\
\hline$i$ & 60.0 & 1.00 \\
\hline $\mathbf{s}$ & 60.0 & 1.00 \\
\hline 1 & 20.0 & 1.00 \\
\hline 1 & 20.0 & 1.00 \\
\hline 1 & 20.0 & 1.00 \\
\hline 1 & 20.0 & 1.00 \\
\hline $\mathbf{g}$ & 20.0 & 1.00 \\
\hline 1 & 20.0 & 1.00 \\
\hline $\mathbf{s}$ & 20.0 & 1.00 \\
\hline 1 & 36.0 & 1.00 \\
\hline$l$ & 36.0 & 1.00 \\
\hline 9 & 36.0 & 1.00 \\
\hline $\mathrm{s} / \mathrm{l}$ & 36.0 & 1.00 \\
\hline 1 & 20.0 & 1.00 \\
\hline$l$ & 20.0 & 1.00 \\
\hline$s / l$ & 20.0 & 1.00 \\
\hline $\mathbf{g}$ & 80.0 & 1.00 \\
\hline $\mathbf{g}$ & 80.0 & 1.00 \\
\hline$i$ & 25.0 & 1.00 \\
\hline
\end{tabular}


TABLE 10

Palladiun Processing Facility flow Sheet

$6.0 \mathrm{~kg}$ Production Batch size

\begin{tabular}{|c|c|}
\hline $\begin{array}{l}\text { Stream No. } \\
========\end{array}$ & $\begin{array}{l}\text { Description } \\
===x== \pm=x=x\end{array}$ \\
\hline 1 & Palladium Sponge \\
\hline 2 & $69.9 \%$ Nitric Acid \\
\hline 3 & 37.2\% Hydrochloric Acid \\
\hline 4 & Nitric Oxide \\
\hline 5 & Unfiltered Redwine \\
\hline 6 & Gold/Platinm \\
\hline 7 & Redwine \\
\hline 8 & 29.9\% Anmonium Hydroxide \\
\hline 9 & Deionized Water \\
\hline 10 & $100 \%$ Acetic Acid \\
\hline 11 & Ammonia Vapors \\
\hline 12 & Unfiltered Vinegar \\
\hline 13 & Iron Hydroxide \\
\hline 14 & Vinegar \\
\hline 15 & $88 \%$ Formic Acid \\
\hline 16 & Carbon Dioxide \\
\hline 17 & Unfiltered Muddy Water \\
\hline 18 & Deionized Water \\
\hline 19 & Waste filtrate \\
\hline 20 & Wet Palladium Pouder \\
\hline 21 & Water Vapor \\
\hline 22 & Dry Palladium Powder \\
\hline 23 & 50.07 Sodium Hydroxide \\
\hline
\end{tabular}

Mass (Kg)
=xa=m=x=as
6.000
42.300
0.006
21.152
27.152
0.030
27.122
19.378
215.311
0.377
nil
262.188
0.131
262.056
5.081
4.858
267.138
270.000
528.588
8.550
2.850
5.700
26.856

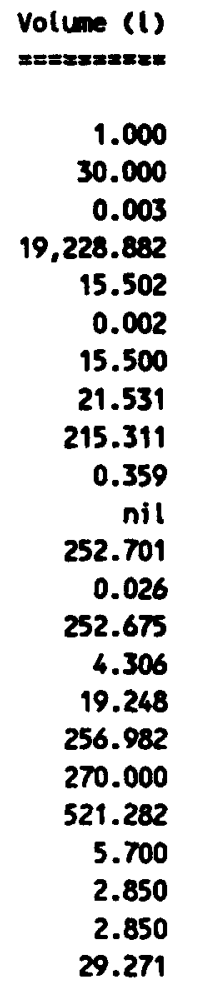

Phase
$x=z=$
8
1
1
9
1
8
1
1
1
1
9
1
8
1
1
9
$5 / 1$
1
1
$8 / 1$
9
9
1

Phase Tenp.

imp. (c)

Pres. (Atm)

6.000

2.300

27.152

19.378

0.377

188

4.858

28.588

26.856
123.0

123.0

123.0

123.0

60.0

60.0

20.0

20.0

20.0

20.0

20.0

20.0

20.0

36.0

36.0

36.0

36.0

20.0

20.0

20.0

80.0

80.0

25.0
=x=m=x=m=E=

1.00

1.00

1.00

1.00

1.00

1.00

1.00

1.00

1.00

1.00

1.00

1.00

1.00

1.00

1.00

1.00

1.00

1.00

1.00

1.00

1.00

1.00

1.00 
TABLE 11

Palladium Processing Facility flow Sheet

$7.0 \mathrm{~kg}$ Production Batch size

\begin{tabular}{cl} 
Stream No. & \multicolumn{1}{c}{$\begin{array}{c}\text { Description } \\
=========\end{array}$} \\
1 & Pall ladium Sponge \\
2 & $69.9 \%$ Nitric Acid \\
3 & $37.2 \%$ Hydrochloric Acid \\
4 & Nitric Oxide \\
5 & Unfiltered Redwine \\
6 & Gold/Plat inum \\
7 & Redwine \\
8 & $29.9 \%$ Ammonium Hydroxide \\
9 & Deionized Hater \\
10 & 100\% Acetic Acid \\
11 & Ammonia Vapors \\
12 & Unfiltered Vinegar \\
13 & Iron Hydroxide \\
14 & Vinegar \\
15 & 88\% Formic Acid \\
16 & Carbon Dioxide \\
17 & Unfiltered Muddy Water \\
18 & Deionized Hater \\
19 & Waste Filtrate \\
20 & Wet Palladium Powder \\
21 & Water Vapor \\
22 & Dry Palladium Powder \\
23 & 50.0\% Sodium Hydroxide
\end{tabular}

Mass $(\mathrm{Kg})$
$=======$
7.000
49.350
0.004
24.677
31.677
0.035
31.642
22.608
251.196
0.440
$\mathrm{nil}$
305.885
0.153
305.733
5.928
5.668
311.661
315.000
616.686
9.975
3.325
6.650
31.332

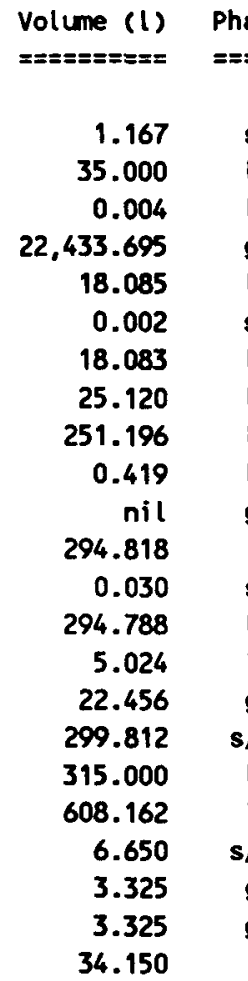

\begin{tabular}{|c|c|c|}
\hline $\begin{array}{l}\text { Phase } \\
=====\end{array}$ & $\begin{array}{l}\text { Temp. (C) } \\
=========\end{array}$ & $\begin{array}{l}\text { Pres. (Atm) } \\
===========\end{array}$ \\
\hline $\mathbf{s}$ & 123.0 & 1.00 \\
\hline 1 & 123.0 & 1.00 \\
\hline$l$ & 123.0 & 1.00 \\
\hline g & 123.0 & 1.00 \\
\hline 1 & 60.0 & 1.00 \\
\hline $\mathbf{s}$ & 60.0 & 1.00 \\
\hline$l$ & 20.0 & 1.00 \\
\hline$l$ & 20.0 & 1.00 \\
\hline 1 & 20.0 & 1.00 \\
\hline l & 20.0 & 1.00 \\
\hline $\mathbf{g}$ & 20.0 & 1.00 \\
\hline$i$ & 20.0 & 1.00 \\
\hline s & 20.0 & 1.00 \\
\hline$l$ & 36.0 & 1.00 \\
\hline 1 & 36.0 & 1.00 \\
\hline 9 & 36.0 & 1.00 \\
\hline s/l & 36.0 & 1.00 \\
\hline 1 & 20.0 & 1.00 \\
\hline 1 & 20.0 & 1.00 \\
\hline $\mathrm{s} / \mathrm{l}$ & 20.0 & 1.00 \\
\hline $\mathbf{g}$ & 80.0 & 1.00 \\
\hline $\mathbf{g}$ & 80.0 & 1.00 \\
\hline$i$ & 25.0 & 1.00 \\
\hline
\end{tabular}


TABLE 12

Palladiun Processing Facility flow Sheet

$8.0 \mathrm{~kg}$ Production Batch size

\begin{tabular}{|c|c|}
\hline $\begin{array}{l}\text { Stream No. } \\
=========\end{array}$ & $\begin{array}{l}\text { Description } \\
===x= \pm x=2=z\end{array}$ \\
\hline 1 & Palladiun Sponge \\
\hline 2 & $69.9 \%$ Nitric Acid \\
\hline 3 & 37.2\% Hydrochloric Acid \\
\hline 4 & Mitric Oxide \\
\hline 5 & Unfiltered Redwine \\
\hline 6 & Gold/Platimun \\
\hline 7 & Redwine \\
\hline 8 & 29.9\% Anmonium Hydroxide \\
\hline 9 & Deionized Water \\
\hline 10 & 100\% Acetic Acid \\
\hline 11 & Ammonia Vapors \\
\hline 12 & Unfiltered vinegar \\
\hline 13 & Iron Hydroxide \\
\hline 14 & Vinegar \\
\hline 15 & 88\% Formic Acid \\
\hline 16 & Carbon Dioxide \\
\hline 17 & Unfiltered Muddy Water \\
\hline 18 & Deionized Mater \\
\hline 19 & Waste filtrate \\
\hline 20 & Wet Palladium Pouder \\
\hline 21 & Water Vapor \\
\hline 22 & Dry Palladium Powder \\
\hline 23 & 50.0x Sodium Hydroxide \\
\hline
\end{tabular}

\begin{tabular}{|c|c|c|c|c|}
\hline $\begin{array}{l}\text { Mass (Kg) } \\
==2 x=5=8=\end{array}$ & $\begin{array}{l}\text { Volume (1) } \\
\text { yxtesx=mx }\end{array}$ & $\begin{array}{l}\text { Phase } \\
x=m=x\end{array}$ & $\begin{array}{l}\text { Temp. (C) } \\
x==x=x=x=\end{array}$ & $\begin{array}{l}\text { Pres. (Atm) } \\
===x======\end{array}$ \\
\hline 8.000 & 1.333 & 8 & 123.0 & 1.00 \\
\hline 56.400 & 40.000 & 1 & 123.0 & 1.00 \\
\hline 0.005 & 0.004 & 1 & 123.0 & 1.00 \\
\hline 28.202 & $25,638.509$ & $\mathbf{g}$ & 123.0 & 1.00 \\
\hline 36.202 & 20.669 & 1 & 60.0 & 1.00 \\
\hline 0.040 & 0.002 & 8 & 60.0 & 1.00 \\
\hline 36.162 & 20.667 & 1 & 20.0 & 1.00 \\
\hline 25.837 & 28.708 & 1 & 20.0 & 1.00 \\
\hline 287.081 & 287.081 & 1 & 20.0 & 1.00 \\
\hline 0.502 & 0.478 & 1 & 20.0 & 1.00 \\
\hline nil & nil & g & 20.0 & 1.00 \\
\hline 349.583 & 336.935 & 1 & 20.0 & 1.00 \\
\hline 0.175 & 0.034 & $\mathbf{s}$ & 20.0 & 1.00 \\
\hline 349.409 & 336.900 & 1 & 36.0 & 1.00 \\
\hline 6.775 & 5.742 & 1 & 36.0 & 1.00 \\
\hline 6.478 & 25.664 & g & 36.0 & 1.00 \\
\hline 356.184 & 342.642 & $8 / 1$ & 36.0 & 1.00 \\
\hline 360.000 & 360.000 & 1 & 20.0 & 1.00 \\
\hline 704.784 & 695.042 & I & 20.0 & 1.00 \\
\hline 11.400 & 7.600 & $s / 1$ & 20.0 & 1.00 \\
\hline 3.800 & 3.800 & $\mathbf{g}$ & 80.0 & 1.00 \\
\hline 7.600 & 3.800 & $\mathbf{g}$ & 80.0 & 1.00 \\
\hline 35.808 & 39.028 & 1 & 25.0 & 1.00 \\
\hline
\end{tabular}


TABLE 13

Palladium Processing Facility flow Sheet 9.0 Kg Production Batch Size

\begin{tabular}{rl} 
Stream No. & \multicolumn{1}{c}{$\begin{array}{c}\text { Description } \\
==========\end{array}$} \\
1 & Palladium Sponge \\
2 & $69.9 \%$ Nitric Acid \\
3 & $37.2 \%$ Hydrochloric Acid \\
4 & Nitric Oxide \\
5 & Unfiltered Redwine \\
6 & Gold/Plat inum \\
7 & Redwine \\
8 & $29.9 \%$ Ammonium Hydroxide \\
9 & Deionized Water \\
10 & 100\% Acetic Acid \\
11 & Ammonis Vapors \\
12 & Unfiltered Vinegar \\
13 & Iron Hydroxide \\
14 & Vinegar \\
15 & 88\% Formic Acid \\
16 & Carbon Dioxide \\
17 & Unfiltered Muddy Water \\
18 & Deionized Water \\
19 & Waste Filtrate \\
20 & Wet Palladium Powder \\
21 & Water Vepor \\
22 & Dry Palladium Powder \\
23 & 50.0\% Sodium Hydroxide
\end{tabular}

\begin{tabular}{|c|c|c|c|c|}
\hline $\begin{array}{l}\text { Mass (Kg) } \\
=========\end{array}$ & $\begin{array}{l}\text { Volume (1) } \\
==========\end{array}$ & $\begin{array}{l}\text { Phase } \\
=====\end{array}$ & $\begin{array}{l}\text { Temp. (C) } \\
========\end{array}$ & $\begin{array}{l}\text { Pres. (Atm) } \\
===========\end{array}$ \\
\hline 9.000 & 1.500 & $\mathbf{s}$ & 123.0 & 1.00 \\
\hline 63.450 & 45.000 & 1 & 123.0 & 1.00 \\
\hline 0.005 & 0.005 & 1 & 123.0 & 1.00 \\
\hline 31.728 & $28,843.323$ & $\mathbf{g}$ & 123.0 & 1.00 \\
\hline 40.728 & 23.252 & l & 60.0 & 1.00 \\
\hline 0.045 & 0.002 & $\mathbf{s}$ & 60.0 & 1.00 \\
\hline 40.683 & 23.250 & 1 & 20.0 & 1.00 \\
\hline 29.067 & 32.297 & 1 & 20.0 & 1.00 \\
\hline 322.967 & 322.967 & 1 & 20.0 & 1.00 \\
\hline 0.565 & 0.538 & $l$ & 20.0 & 1.00 \\
\hline nil & nil & $\mathbf{g}$ & 20.0 & 1.00 \\
\hline 393.281 & 379.051 & I & 20.0 & 1.00 \\
\hline 0.197 & 0.038 & $\mathbf{s}$ & 20.0 & 1.00 \\
\hline 393.085 & 379.013 & 1 & 36.0 & 1.00 \\
\hline 7.622 & 6.459 & I & 36.0 & 1.00 \\
\hline 7.287 & 28.872 & g & 36.0 & 1.00 \\
\hline 400.707 & 385.472 & s/l & 36.0 & 1.00 \\
\hline 405.000 & 405.000 & I & 20.0 & 1.00 \\
\hline 792.882 & 781.922 & $l$ & 20.0 & 1.00 \\
\hline 12.825 & 8.550 & s/l & 20.0 & 1.00 \\
\hline 4.275 & 4.275 & $\mathbf{g}$ & 80.0 & 1.00 \\
\hline 8.550 & 4.275 & g & 80.0 & 1.00 \\
\hline 40.284 & 43.907 & I & 25.0 & 1.00 \\
\hline
\end{tabular}

